\title{
COMPUTERS, LEARNING OUTCOMES, AND THE CHOICES FACING STUDENTS
}

\author{
Lester Hadsell \\ University at Albany \\ and \\ Gerald T. Burke \\ University at Albany
}

\section{INTRODUCTION}

The inconclusive findings of years of research on the effectiveness of computers in education highlight the need for a new approach to thinking about the issue. We believe economic analysis offers such an approach. Making this new approach critical at this time is the great impetus and wide-spread public support that currently exists for spreading the computer to schools nationwide and the associated costs [Barron, et al., 2003; No Child Left Behind Act of 2001; Milken, 1998; President's Committee of Advisors on Science and Technology, 1997].

Considering the financial nature of the issue, economists have been remarkably quiet. As we discuss below, education researchers have taken the lead in examining the role of computers in achieving higher levels of learning while economists have provided evidence mostly concerning the effectiveness of particular uses of computers in the economics classroom [e.g., Moini, 1996; Greenlaw, 1999; Murray, 1999; Savage and Law, 2003; Schmidt, 2003], leaving largely unaddressed the bigger issue of computer effectiveness beyond the economics classroom. A notable exception is a recent study of Israeli elementary and middle school students by Angrist and Lavy [2002].

Notwithstanding the extensive empirical research, two basic questions remain: (1) Are computers productivity enhancing tools? That is, do computers allow students to achieve a greater level of learning per unit of time studying? And (2), does learning increase? That is, are measurable learning outcomes present? The two questions, while similar and entwined, are not the same. The first is purely technical. The second asks something about students' commitment to learning and the requirements set for them. We illustrate how the answer to the first can be "yes" while at the same time the answer to the second may be "no."

We argue that the empirical research to date lacks a full accounting of one important factor, student choice, thereby missing important information. The framework we present, while straightforward, can reconcile seemingly contradictory empirical findings (such as a "yes" answer to the first question noted above and a "no" to the second). By using the framework we can identify whether computers are productivity

Lester Hadsell: School of Business, University at Albany, 1400 Washington Avenue, Albany, New York 12222. E-mail: hadsell@albany.edu.

Eastern Economic Journal, Vol. 33, No. 1, Winter 2007 
enhancing tools and how likely it is that learning will increase (again, two separate questions). It offers insight into how the effectiveness of computers can be increased and also allows us to identify students who would benefit most and those who would benefit least or who need the most assistance to achieve the benefits others obtain.

Section II summarizes the primary research findings regarding computers in education, from elementary school through college. The next section describes the model. We then present findings from a case study. We conclude with comments, a discussion of the primary implications, and suggestions for future research.

\section{BACKGROUND}

The evidence concerning the effectiveness of computers in helping students learn is wide ranging. Some studies support the notion that computers lead to increased learning outcomes [Waxman, Connell, and Gray, 2002; Schacter, 2001; Sivin-Kachala, 1998]. Other studies have reported little or no gain and, sometimes, negative effects [Goldberg, et al., 2002; Cuban, 2001; Wenglinsky, 1998]. Angrist and Lavy [2002], among the first economists to explore this subject in depth, find no statistically significant relationship between computer aided instruction and learning outcomes in an investigation of student and teacher performance at the elementary and middle school level in Israel.

Taken as a whole the empirical work has found increased use of computers without clear, conclusive evidence of their effectiveness. What makes these findings especially troubling is the common perception of the usefulness of computers. If computers are productivity enhancing tools then where are the results? Prior attempts to reconcile the contradictory empirical findings have focused on identifying flaws in research methodology or simply differences in how the research was conducted: type of computer, type of students, time frame, or outcome measure [Slattery and Kowalski, 1998; Bangert-Drowns, 1993; Hawisher, 1989; Angrist and Lavy, 2002]. Angrist and Lavy [2002], for example, offer three possible explanations for their findings. First, that computers are "no better and may be less effective than other teaching methods." Second, the transition to effectively using computers takes time, with significant results perhaps extending beyond the period of their study. Third, the extensive costs of computerization, which crowds out spending in other areas of education, negating the beneficial aspects of computers.

All of these may play a role but we focus on differences among students (within and across studies) as the primary explanation for the mixed empirical results. Even when students are of an apparently homogeneous group (e.g., college freshmen or high school seniors) differences within the group exist with regard to attitudes toward computers, comfort and experience with computers, attitudes toward learning, and social factors influencing choices they make regarding their effort. Slattery and Kowalski [1998] identify "social factors" as possibly playing a role in differences in the effectiveness of computers for student sub-groups. These social factors include work and family demands beyond the classroom. We incorporate these factors into a model that values student choices as a key input. 
Our attention is focused on where students have the greatest choice over whether or not to study. This typically means outside the classroom where students use computers to complete assignments: writing papers, gathering information, communicating with others [Kozma, 2003; Barron, et al., 2003; Duderstadt, et al. 1999; Milken, 1999]. Most importantly for our model, it is outside the classroom that students are able to express their preferences (within certain limits) for learning and for other activity, the two primary components in our model.

A central factor determining whether computers lead to greater learning outcomes is student effort. Students have choices - choices concerning how much time and effort to devote to their learning and what level of learning they want to achieve. In simplified terms, students' time can be grouped into two categories: time spent studying for a particular course (meant to encompass all time devoted to learning for that course) and time spent in all other activity (including, inter alia, learning for other courses). If the computer is a productivity enhancing tool, students will learn more per unit of study time. Depending on the type of student and how much time is devoted to learning, the increased productivity could lead to more learning, the same amount of learning, or even less (if the student has a great dislike for learning or, in other words, a strong preference for other activity). As we will show below, the same outcomes are possible if the computer is not a productivity enhancing tool.

Our goal in this paper is not to conclude whether or not computers help students learn, although we do present preliminary empirical findings later, but rather to provide a framework for thinking about how the effectiveness of technology generally can be studied. We use standard microeconomic analysis [e.g., Nicholson, 1992] to show not only that the effectiveness of computers may be inferred from the changes in learning outcome and time devoted to achieve that outcome but also the counterintuitive observation that computers may both be beneficial to the learning process (a productivity enhancing tool) and result in outcomes that are no better or even worse than without computers.

\section{MODEL}

We call the learning outcome "grades" and the non-course activity "leisure" (which may truly be "leisure," as well as employment and other activity) and assume that students maximize their utility, which is a function of grades $(G)$ and leisure $(L)$. Knowing what shapes students' utility, why students choose different combinations of $G$ and $L$, is crucial to explaining key observations in our model. Consequently, we suggest that student preferences are derived from the characteristics of $G$ and $L$, following the approach taken by Lancaster [1966] and Lipsey and Rosenbluth [1971]:

$$
U=U\left(c_{1}, \ldots, c_{n}\right)
$$

$$
\text { where } c_{i}=a_{i 1} G+a_{i 2} L \text {, }
$$

where $a_{i 1}, a_{i 2}$ represent the fixed quantity of each characteristic $\left(c_{i}\right)$ in each good. Goods are consumed for the characteristics that they provide: for example, for food and bever- 
ages these characteristics might be calories and alcoholic content, or, for rice and all other foods they might be calories and "taste," as in Jensen and Miller [2002].

In our model, we identify two characteristics, short-term reward $\left(c_{1}\right)$ and long-term reward $\left(c_{2}\right)$. Short-term reward represents benefits from the good that are enjoyed today, whereas long-term reward represents benefits from the good that are enjoyed in the future, even though the good is consumed today. It is easy to imagine that for most students the utility from grades comes more from its long-term reward (in the form of increased income, greater career choice, and associated benefits), rather than its short-term reward, even though it has both. On the other hand, we can imagine that the utility from non-course activity (e.g., most types of student employment) comes more from its short-term reward (e.g., income earned) than its long-term reward (e.g., work experience or marketable skills). ${ }^{1}$ Students will choose a combination of $G$ and $L$ that maximizes utility with these qualities in mind.

Of particular importance to our discussion later (of the outcomes in Figure 2) is the possibility that some students may be (or perceive themselves to be) constrained in their choices of $G$ and $L$ by a certain minimum required level of long-term reward. The basis of this type of constraint might be found, for example, in job announcements that require a varying combination of academic skills and work experience. ${ }^{2}$ This minimum requirement can be expressed via an additional constraint in the characteristics-based model [Lipsey and Rosenbluth, 1971] and can also be expressed in the shape of the utility curves of standard consumer theory, as the characteristics-based approach to consumer theory and standard utility theory are shown by Jensen and Miller [2002] to be equivalent when utility is defined:

$$
U(G, L)=\left\{\begin{array}{ll}
{[(G+L-x) /(G+L-(x-.01))] G^{\frac{1}{6}} L^{\frac{5}{6}}} & \text { if } G+L \geq x \\
0 & \text { if } 0 \leq G+L<x
\end{array}\right\}
$$

where $x$ represents the minimum combined level of $G$ and $L$. When total units of $G$ and $L$ much exceeds $x$ then the utility is Cobb-Douglas, resembling the curves in Figure 1 . When $G+L$ approach $x$, however, utility rapidly declines to 0 and the shape of the utility curves resemble those in Figure $2 .{ }^{3}$ Thus, it is as if the consumer faces a minimum reward constraint at $G+L=x$ units of total consumption, which might be binding when the student must devote many hours to generating short-term reward from $L$ and has little time to generate $G$.

Four possible learning-leisure outcomes (and two types of students) are illustrated in Figure 1. The diagrams illustrate the potential effects on learning and leisure when computers are effective learning tools, as in 1(a) and (b) and when computers hinder learning, as in 1(c) and (d).

$G^{*}$ and $L^{*}$ are the initial (pre-computer) levels of learning and leisure based on student preferences represented by $U^{*}$ and a time constraint $T$. The time constraint is similar to a budget constraint and reflects the limited time in each day, which can be used for either study or leisure:

$$
S+L=24 \text {. }
$$


If we assume a student's grade is a linear function of time spent studying then

$$
G=\varepsilon S
$$

where $\varepsilon$ represents the student's efficiency at converting study time into learning. If the computer is a productivity enhancing tool then $\varepsilon$ increases when computers are used. Note that by virtue of equations 4 and 5, when the efficiency with which students can convert study time into learning rises, the 'price' of learning declines -- the student must give up less leisure to gain the same amount of learning. If students maximize their utility subject to the time constraint then the efficiency at converting study time into learning is the ratio of the marginal utility of leisure to the marginal utility of learning: $\varepsilon=M U_{L} / M U_{G}$.

\section{FIGURE 1}
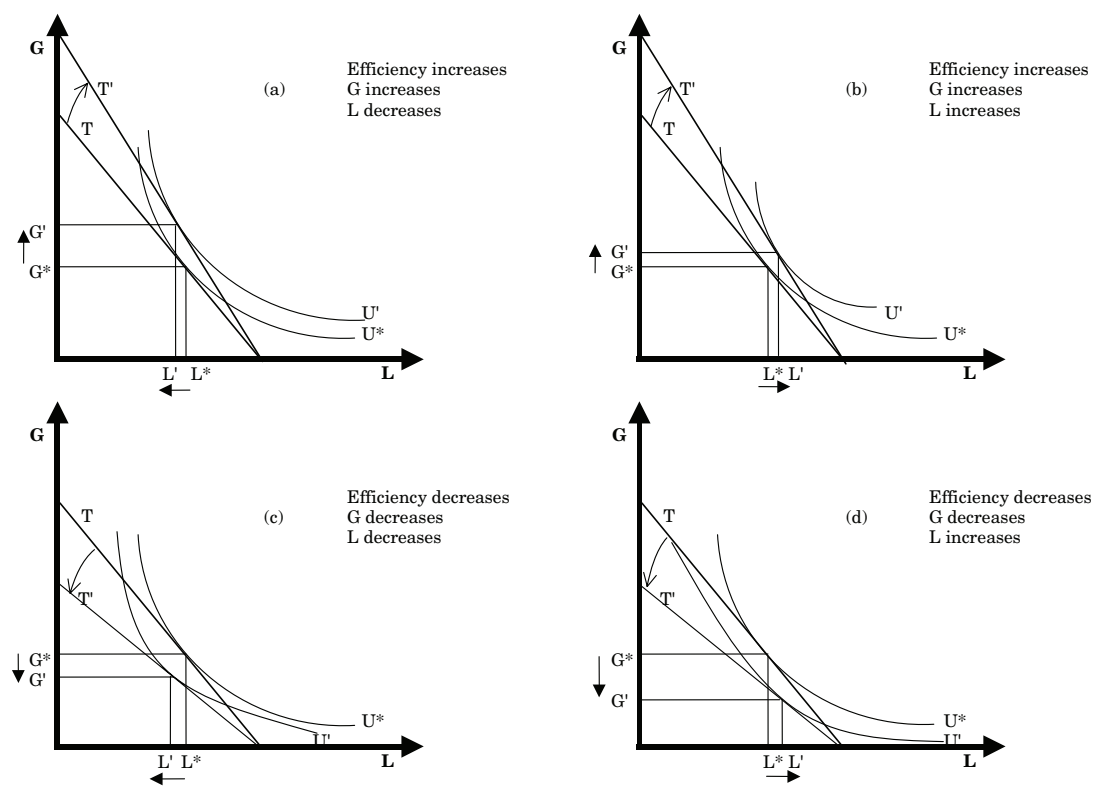

Learning and leisure combinations after the introduction of a new techinology that either increases efficiency (panels a and b) or decreases efficiency (panels $\mathrm{c}$ and d).

$\mathrm{G}=$ Grades, a learning outcome measure, $\mathrm{L}=$ Leisure, a measure of time devoted to all other activities,

Panel (a) in Figure 1 is the case in which student learning increases the most when computers are used. Here the effectiveness of turning study time into learning by using a computer increases. With student preferences represented by $U$ and $U$ ', the use of computers leads to more learning. But it also leads to less leisure, as students in this category devote additional time to learning. In effect, the computer reduces the price of obtaining a higher level of learning so students 'buy' more of it, even spending more of their time than before. Students in 1(a) have a strong preference for learning (and a relatively greater emphasis on long-term benefits).

In Panel (b), both learning and leisure increase. The productivity benefits from the computer are split between a higher level of learning and less time needed to achieve 
that learning. The difference between panels (a) and (b) is not the effectiveness of the computer, as the magnitude of the rotation of $T$ to $T^{\prime \prime}$ is the same in both cases, but the shape of the student's utility. Panels (a) and (b) represent different types of students - students in (b) have a strong preference for leisure and are less motivated by learning than are students in (a). Panels (c) and (d) show that if the computer is not a productivity enhancing tool then the movements of $G$ are reversed.

\section{FIGURE 2}

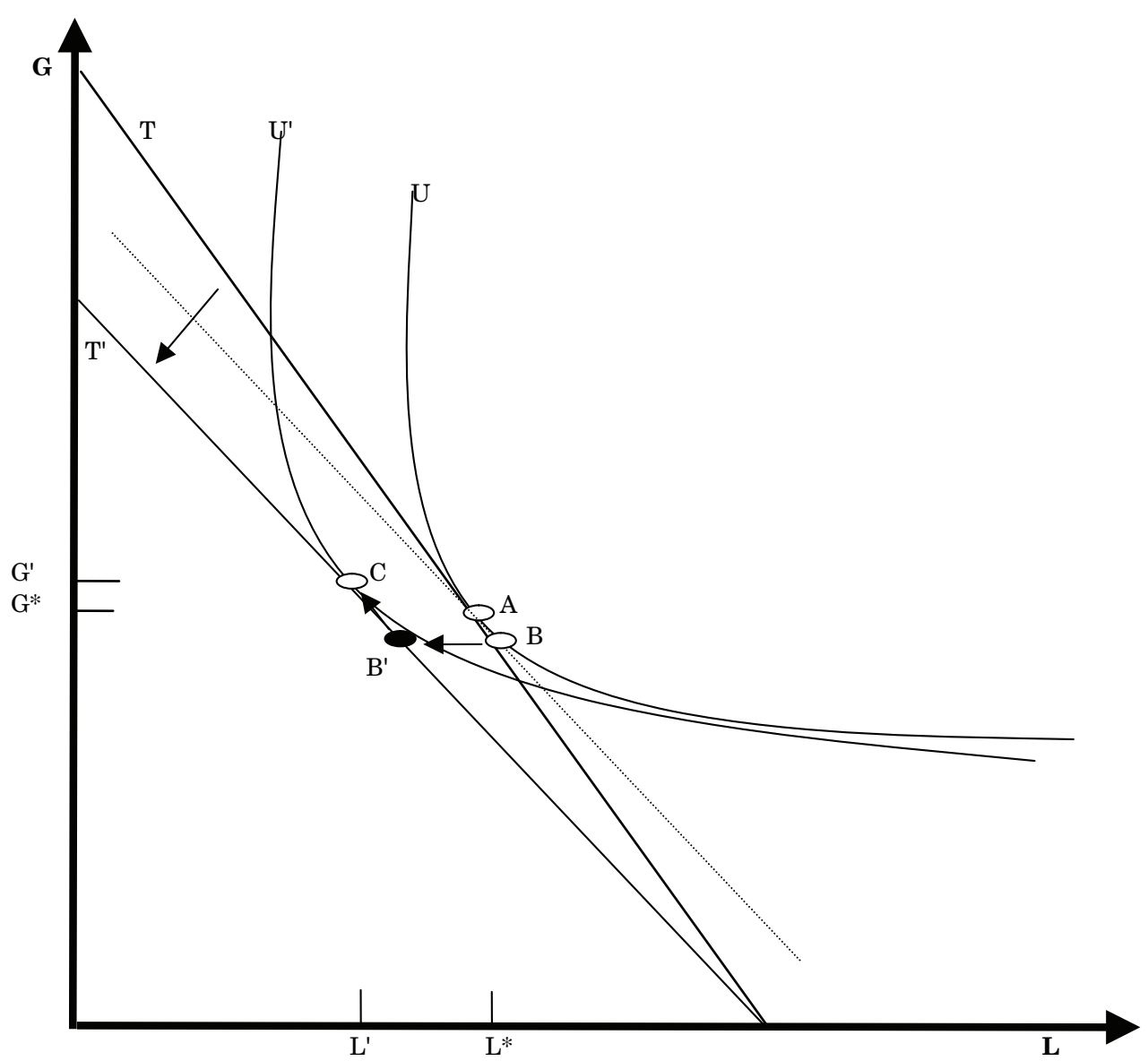

Learning and leisure combinations before $\left(G^{*}, L^{*}\right)$ and after $\left(G^{\prime}, L^{\prime}\right)$ the introduction of a new technology that decreases efficiency

At the starting point, A, the student just satisfies the minimum required level of long-term reward. B (and B') is below the required level of long-term reward. At $\mathrm{C}$, the new equilibrium, the minimum level is again attained.

We will refer to the outcome depicted above as region 2(a) in Fig 3 . The corresponding outcome when $\mathrm{T}$ rotates in the other direction will be referred to as region $2(\mathrm{~b})$. 
Two more possibilities exist, however. Using computers may actually lead to lower learning outcomes, even if they are effective tools, or higher learning outcomes even if they are ineffective tools, as shown in Figure 2. These peculiar outcomes result when students' choices are constrained by a minimum long-term reward requirement. For example, when they must have some combination of $G$ and $L$ to satisfy the employment application criteria noted earlier, but are unable to exceed the minimum. In Figure 2, movement from $\mathrm{A}$ to $\mathrm{C}$ consists of both a substitution effect from the change in relative prices (from A to B) and an income effect (from B to C). The income effect means a reduction in available leisure (students must study more to obtain the same level of $G$ ) - which causes a small reduction in long-term reward (to B', which is below its minimum required level) as $L$ is reduced. Seeking to reestablish the desired minimum level of long-term reward, the student trades Leisure, with its low long-term reward, for Grades, with its high long-term reward, until the minimum level of long-term reward is reached again at C. For example, students who lose work experience (as $L$ is reduced because of the negative income effect) must make up for it by obtaining more academic skills.

In the case when the computer improves efficiency, the same effect works in the opposite direction. An increase in available time, if taken entirely in increased leisure but without a reduction in $G$, would (for these students) lead to more than their required long-term reward - as the time constraint loosens they prefer to consume much more $L$. In both cases, students in Figure 2 have a strong preference for $L$ but are constrained in their expression for it by their recognition of the far greater, and necessary, long-term reward from learning. ${ }^{4}$

The negative "income" effect evidenced in these two cases is so strong that learning resembles a Giffen good - a good so "inferior" that the quantity demanded rises even as its price increases. ${ }^{5}$ Yet, the "inferiority" of learning results from its greater long-term reward - a sign of "inferiority" only in the economic sense. Note that Jensen and Miller [2002] use the same approach to explain Giffen-type behavior observed in China.

The possibilities in Figure 2 add ambiguity concerning the measurement of the effectiveness of computers. This is seen in Figure 3, which combines Figures 1 and 2, showing the percentage changes in grade and leisure between no-computer-use and computer use $\left(\% \Delta G=\ln \left(G^{\prime} / G^{*}\right)\right.$ and $\left.\% \Delta L=\ln \left(L^{\prime} / L^{*}\right)\right)$. The dotted line indicates the locus of points for which the computer has no effect on productivity $\left(\% \Delta \varepsilon=\ln \left(\varepsilon^{\prime} / \varepsilon^{*}\right)\right.$ $=0)$. Along this line, $\% \Delta G=\% \Delta S=\% \Delta(24-L) .{ }^{6}$ To the left of the dotted line, $\% \Delta \varepsilon<0$ (productivity decreases), corresponding to panels (c) and (d) in Figure 1 and Figure 2. To the right of the dotted line, $\% \Delta \varepsilon>0$ (productivity increases), corresponding to panels (a) and (b) in Figure 1 and the mirror of Figure 2. The placement of this line depends on the initial level of $L$ - the higher the level for $L$ the more vertical it becomes; when $L$ equals $S$ then the line is $45^{\circ}$ from the axis.

Prior studies that indicate higher learning outcomes without measuring $\Delta S$ may place students in the 2 a region in Figure 3, falsely indicating that the computer is a productivity enhancing tool. Studies that indicate a decrease in learning outcomes may place students in the $2 \mathrm{~b}$ region in Figure 3, falsely indicating that the computer is not a productivity enhancing tool. Thus, studies that measure only learning outcomes 
are potentially getting it wrong when drawing conclusions about the effectiveness of computers. More needs to be known about time students devote to learning before we are able to draw conclusions about the productivity of the new technology and the learning outcomes that are likely to result.

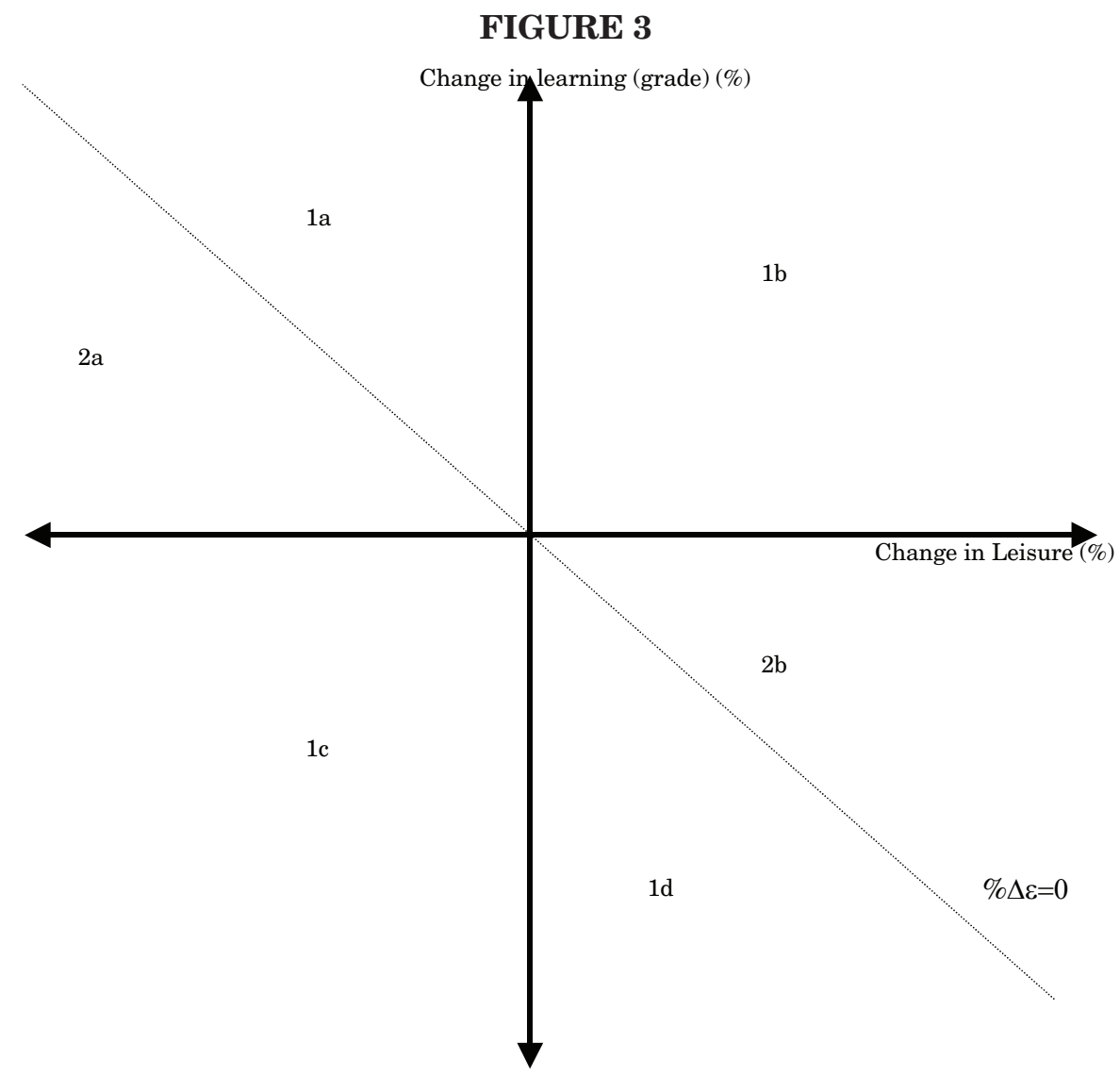

Outcomes space measuring effects of computer use, derived from Figures 1 and 2.

Change in learning $($ grade $)=\ln \left(G^{\prime} / G^{*}\right)$, and change in leisure $=\ln \left(L^{\prime} / L^{*}\right)$, where $*$ indicates pre-computer outcome and ' indicates post-(or without) computer outcome. The dotted line indicates no change in productivity, pre- to post- computer use (\%change in $\mathrm{G}=\%$ change in $\mathrm{S}$ ). The exact position of this line depends on the starting value for $\mathrm{L}$.

Below the dotted line, the computer reduces productivity: changes in studytime exceed changes in learning.These areas correspond to panels (c) and (d) in Figure 1 and the outcome in Figure 2. Above the dotted line, the change in learning exceeds the change in studytime (time devoted to learning): the computer is a productivity-enhancing tool. correspond to panels (a) and (b) in Figure 1 and the mirror of Figure 2.

Would a student actually choose a less efficient technology, placing them to the left of the dotted line? Perhaps not on their own, if they are fully informed and grades are the only outcome associated with S. But, it is plausible that students may not 
realize that they are using an inferior technology. They may also feel peer pressure to produce non-graded outcomes associated with the computer such as fancy lettering, graphics, presentation generally (style over substance). ${ }^{7}$ Perhaps the most obvious reason for students choosing an inferior technology, though, is that students may be forced into using the new technology by teachers who require that assignments be typed (which today means computer generated) or work be researched on the Internet (instead of from books).

Because individual students may have their own $\varepsilon$ and $\Delta \varepsilon$, depending on their preparation and preferences, different students will fall into different categories. Imposing a one-size-fits-all technology approach may help some students and hurt others. It follows for example, that, contrary to conventional thought, computers may not act entirely as a democratizing force, leveling the academic playing field, but instead as a reinforcer of academic separation, separating the better-prepared, motivated, and future-oriented from the less-prepared, less motivated, and now-oriented. As noted earlier, the gap might also be expected to widen between students without many time commitments outside class and those who have many (i.e., are time-constrained). The potential of a minimum long-term reward requirement (for students in region 2b) highlights the importance of raising standards. An exogenously determined minimum standard would limit the possibility of region 2 (b) outcomes.

Finally, we note that the utility-maximizing-student model may be most appropriate for students with the greatest choice between leisure and learning and those for whom the potential for computer use outside the classroom is greatest. This means, perhaps, college-age and secondary students but not so much for elementary school students.

\section{CASE STUDY}

To illustrate implementation of our model, we undertook a small-scale empirical investigation using a single section of college freshman-level writing as our base. While far from definitive, the results provide insight into the challenges of evaluating the effectiveness of computers. We measured changes in study time $(S)$ and learning outcomes $(G)$, addressing the two basic questions noted in the introduction: (1) Are computers productivity enhancing? And, (2) does learning increase when computers are used? We were then able to place the findings in the framework provided by the model.

The study focused on college-level Composition II in the spring semester of $2003 .{ }^{8}$ We chose composition because computers have greatly simplified the primary aspects of tasks in this course: writing, editing, and rewriting. Students also often perform these activities when completing work for other courses [Becker, 1999]. Students normally have engaged in writing activities before the course and expect to do so afterward. Composition also has been the focus of many empirical studies with the kind of ambiguous findings evident elsewhere. Positive effects of incorporating computers into the writing process are reported by Rodrigues [1985], Bridwell-Bowles, Johnson, Brehe, [1987], McAllister and Louth [1988], and Owston, Murphy, Wideman 
[1992], Raef [1996], and Russell, et al. [2003], among others. Others have found no such effects [Collier, 1983; Hawisher, 1987; Hill, Wallace, and Haas, 1991; Joram, et al, 1992; Meem, 1992; Markel, 1994; Lichtenstein, 1996; Slattery and Kowalski, 1998]. Some have even found a negative relationship between computer use and learning outcomes. Haas [1989, 1990], for example, found decreased levels of planning and formulating of ideas. Harris [1985, p. 330] argued that "inexperienced writers seem even less inclined to make major changes in the content and organization of their texts" when using computers to compose. Daiute [1986, p. 153] found that most "students made significantly fewer revisions when they worked on the computer than when they worked in pen." Dobberstein [1990] notes, "Despite the usefulness of computers, there is no consistent objective evidence that they can help students become better writers." While reports of negative effects may reflect the newness of the technology at the time of the studies, later studies, such as those by Wenglinsky [1998], also have found mixed results. Goldberg et al. [2002] provide a full review of the computers-and-writing literature.

TABLE 1

Average Time to Completion of Assignment and Revision for Grade Improvement

Technology Computer Pen/pencil

Initial completion of assignment

Average time to complete draft (minutes)

Average time to complete revision assignment (minutes)

Average grade (all students)

$\begin{array}{cc}57 & 40 \\ 57 & 39 \\ 82.2 & 83.8\end{array}$

Revisions after initial completion of assignment

Number of Students who revised the assignment

Average Grade of students who revised (before revisions)

Average Increase in Grade

Average Grade of students who revised (after revisions)

$\begin{array}{cc}6 & 2 \\ 80.2 & 85.0 \\ 5.8 & 3.8 \\ 86.0 & 88.8\end{array}$

Twenty-three students were first surveyed at the beginning of the semester for demographic and attitudinal information. Most had serious time constraints: 71 percent of the students reported that they were employed; of those who worked, the average work week was reported to be 30.2 hours; the average credit hour load was 12.8. The vast majority ( 85 percent) reported that they were "comfortable" working with computers and three-quarters reported that they normally spent the majority of their time doing writing assignments on the computer.

We recorded students' study time ( $S$ in our model) and the learning outcomes $(G)$ on two 300 to 500-word essays. These were completed during class time, so that their study time could be accurately measured, but were in other respects the same as any out-of-class assignment where the student had choices regarding how much time to devote to the assignment (students were free to leave at any time). One assignment was done with a word processor and one was handwritten (both under the observation of the instructor). Both were graded according to strict departmental guidelines, ensuring consistency. For each assignment, one class period was devoted to complet- 
ing a draft and one period for revising. Students were also offered the opportunity, post grading, to improve their grade through additional revision. Table 1 presents a summary of our findings.

For the class as a whole, time doing the initial drafting and revising was much higher and the grade statistically unchanged for the assignment completed on the computer compared to the hand-written one. Yet, students were more likely to take the opportunity to improve their grade through post-grade revision when the computer was the writing tool. (Two other assignments not completed under the teacher's direct supervision produced similar results, based on anonymous surveys of the students.) What is somewhat surprising is the small number of students who took advantage of the opportunity for post-grade revision, even with the revision-friendly tool. We interpret the lack of interest in post-grade revision to reflect many students' relatively greater valuation of leisure over grades.

Individually, just two of the 23 students fall into the quadrant in Figure 3 indicating the certain effectiveness of computers as a learning tool (the upper right), with more leisure and the same or higher grade. Seven students are in the quadrant indicating the certain ineffectiveness (the lower left). Fourteen are in the ambiguous quadrants, the lower right (2) and the upper left (12). None of these 12 students are in the area where the computer is an efficient tool $-\% \Delta G<\% \Delta S$ for each of them. Without considering time, one would mistakenly attribute the increase in grade for all 12 students to the effectiveness of computers. This is the fundamental problem with prior empirical research that our model has sought to highlight.

\section{CONCLUDING REMARKS}

This paper presents a straightforward model that provides a framework for addressing the primary questions facing researchers of the effectiveness of computers in achieving greater learning outcomes: (1) Are computers productivity enhancing tools? And (2), are measurable learning outcomes present? We show that the two questions, while similar, are not the same and that a model of student choice can be useful in separating them. The empirical research to date offers a range of opinions on the first question and is ambiguous on the second. This is so, we argue, because the research lacks a full accounting of the choices students make, thereby potentially missing important information.

The strength of the framework is that it recognizes student choice as a key ingredient in determining whether using computers leads to higher learning outcomes. The framework can identify whether computers are productive tools in the learning process and how likely it is that learning will increase. It is able to explain disparate results (computers are effective and learning outcomes don't improve, as in Angrist and Lavy [2002]] and offers insight into how the learning outcomes can be increased. It also allows us to identify students - we identify three types, differentiated by the emphasis they place on the reward from learning and leisure - who would benefit most and those who would benefit least.

Our hope is that the framework developed in this paper is used in future empirical work. We think the explicit recognition of student choices and affinities for computers 
and for their academic subject(s) and their commitments outside of class is vital to understanding the impact this latest technology will have on learning outcomes. Additional empirical study, involving more students, a longer time period, and different technologies, should be the focus of future research. Determining the exact nature of the constraints that underlie Figure 2, and the type of student in this category, should be the subject of important future research as well. For instance, our empirical findings that grades for most students are little changed after introduction of the computer, even though their time devoted to completing the work increases, could reflect "grade targeting" - students seeking a certain grade almost regardless of the time required to achieve it. While such behavior can be explained by the choice model we present, whether this is an appropriate explanation for the actual outcomes needs to be investigated.

Future research could also investigate long-term dynamics. What may be true in the short-run may not of course be true in the long-run. Students who initially take all of the efficiency gains in the form of leisure may be compelled in the longrun, through competition for grades, to take more of the efficiency gains in the form of higher G. This might occur if the teacher adjusts the learning standard or as the long-term reward constraint loosens. Students also may, over time, move from one area to another (in Figure 3), as the technology becomes more familiar to them. Such insights could help in understanding student behavior, the impact of technology in education, and appropriate policy.

\section{NOTES}

We thank an anonymous reviewer and the editor, Jim Butkiewicz, for their detailed attention and helpful suggestions.

1. Thus, for $\mathrm{G},\left(a_{21}>a_{11}\right)$; for $\mathrm{L},\left(a_{22}<a_{12}\right)$; and $\left(a_{21}>a_{22}\right)$ - the long-term reward in $\mathrm{G}>$ long-term reward in L.

2. For instance “...applicants must have a BA (or GPA level, or particular academic skills or proficiency (certain level of G)) with 4 years relevant experience (a subset of L), or an MA with 2 years experience...." Of course, often these are only minimum requirements, with additional education and experience needed to secure employment.

3. Sample utility curves from such a formulation are shown in Jensen and Miller [2002].

4. In a similar vein, but under somewhat different circumstances, we could also explain the outcomes in Figure 2 by referring to another commonly observed phenomenon at the college level: reimbursement from employers that some students receive based on their grades. An "A" might garner 100 percent reimbursement, a "B" 80 percent, and so on.

Grade "targeting," or students seeking no more or less than a minimum acceptable grade, may be reacting to either a reimbursement influence or a minimum long-term reward constraint. A third explanation for the outcome shown in Figure 2 is that the new technology makes the process of learning more enjoyable even if it is less effective (i.e., more time-consuming) - students will study more, learn more, and earn a higher grade, because the work is more enjoyable.

5. An "inferior good" is defined as one for which, in response to change in its price, the substitution effect is partially off-set by a negative income effect. When prices of inferior goods rise quantity demanded falls, but not by as much as for a "normal good" (for which the income effect reinforces the substitution effect). Giffen goods are extreme examples of inferior goods; goods for which the negative income effect fully off-sets the substitution effect.

6. Let $G^{*}=\varepsilon^{*} S^{*}$ represent the outcome with no computers and $G^{\prime}=\varepsilon^{\prime} S^{\prime}$ represent the outcome with computers. Taking the natural $\log$ of $\mathrm{G}^{*}-\mathrm{G}^{\prime}$ and rearranging provides: $\% \Delta \mathrm{G} \cong \% \Delta \varepsilon+\% \Delta \mathrm{S} \cong \% \Delta \varepsilon+$ $\% \Delta(24-\mathrm{L})$. 
7. See Goldberg et al. [2002] for other potential learning outcome measures.

8. One of the authors is also an adjunct instructor of English at a nearby community college, where the empirical portion was completed.

\section{REFERENCES}

Angrist, J. and Lavy, V. New Evidence on Classroom Computers and Pupil Learning. The Economic Journal, October 2002, 735-765.

Bangert-Drowns, R. The Word Processor as an Instructional Tool: A Meta-Analysis of Word Processing in Writing Instruction. Review of Educational Research, Spring 1993, 69-93.

Barron, A., Kemker, K., Harmes, C., and Kalaydjian, K. Large-Scale Research Study on Technology in K-12 Schools: Technology Integration as It Relates to the National Technology Standards. Journal of Research on Technology in Education, Summer 2003, 489-500.

Becker, H. Internet Use by Teachers: Conditions of Professional Use and Teacher-directed Student Use. Irvine, CA: Center for Research on Information Technology and Organizations, 1999.

Bridwell-Bowles, L., Johnson, P., and Brehe, S. Writing in Real Time; Composing and Computing: Case Studies of Experienced Writers, edited by Ann Matsuhashi. Norwood, NJ: Ablex, 1987.

Collier, R. The Word Processor and Revision Strategies. College Composition and Communication, May 1983, 149-155.

Cuban, L. Oversold and Underused: Computers in the Classroom. Cambridge, Mass.: Harvard University Press, 2001.

Cudd, M., Tanner, J., and Lipscomb, T. A Profile of Classroom Technology Usage in Finance Instruction. Journal of Financial Education, Spring 2004, 28-40.

Daiute, C. Physical and Cognitive Factors in Revising: Insights from Studies with Computers. Research in the Teaching of English, May 1986, 141-159.

Dobberstein, M. What Good are Computers in the Writing Classroom? New Directions for Teaching and Learning, Winter 1990, 83-89.

Duderstadt, J., Atkins, D., Van Houweling, D. Higher Education in the Digital Age. Westport, CT: Praeger, 1999.

Gilley, O. and Karels, G. In Search of Giffen Behavior. Economic Inquiry, January 1991, 182-189.

Goldberg, A, Russell, M., and Cook, A. Meta-Analysis: Writing with Computers 1992-2002. Accessed at http://www.bc.edu/research/intasc/PDF/Meta_Writing Computers.pdf., 2002.

Greenlaw, S. Using Groupware to Enhance Teaching and Learning in Undergraduate Economics. Journal of Economic Education, Summer 1999, 33-42.

Haas, C. How the Writing Medium Shapes the Writing Process: Effects of Word Processing on Planning. Research in the Teaching of English, May 1989, 174-207.

Composing in Technological Contexts: A Study of Note-making. Written Communication, October 1990, 512-547.

Harris, J. Student Writers and Word Processing: A Preliminary Evaluation. College Composition and Communication, October 1985, 323-330.

Hawisher, G. The Effects of Word Processing on Revision Strategies of College Freshmen. Research in the Teaching of English, May 1987, 145-159.

. Computers and Writing: Where's the Research? English Journal, January 1989, 89-91.

Hill, C, Wallace, D., and Haas, C. Revising On-line: Computer Technologies and the Revising Process. Computers and Composition, November 1991, 83-109.

Jensen, R. and Miller, N. Giffen Behavior: Theory and Evidence. John F. Kennedy School of Government, Harvard University, Faculty Research Working Paper Series, RWP02-014, 2002.

Joram, E., Woodruff, E., Bryson, M. and Lindsay, P. The Effects of Revising with a Word Processor on Written Composition. Research in the Teaching of English, May 1992, 167-193.

Kirkpatrick, H. and Cuban, L. Computers Make Kids Smarter -- Right? Technos Quarterly for Education and Technology, Summer 1998.

Kozma, R. Technology and Classroom Practices: An International Study. Journal of Research on Technology in Education, Fall 2003, 1-14.

Lancaster, K. A New Approach to Consumer Theory. Journal of Political Economy, April 1966, 132157. 
Lichtenstein, N. The Effect of Word Processing on Writing Achievement. ERIC Document Reproduction Service No. 394146, 1996.

Lipsey, R. and Rosenbluth, G. A Contribution to the New Theory of Demand: A Rehabilitation of the Giffen Good. The Canadian Journal of Economics, May 1971, 131-163.

Markel, M. Behaviors, Attitudes, and Outcomes: A Study of Word Processing and Writing Quality among Experienced Word-processing Students. Computers and Composition, 1994, 49-58.

McAllister, C. and Louth, R. The Effect of Word Processing on the Quality of Basic Writers' Revisions. Research in the Teaching of English, December 1988, 417-427.

Meem, D. The Effect of Classroom Computer Use on College Basic Writers. Research and Teaching in Developmental Education, Spring 1992, 57-69.

Milken Exchange on Education Technology Public Opinion Poll. Accessed at http://www.mff.org/ pubs/ME162_98.pdf., 1998.

Focus on Students: Teens Speak Out about Technology in Schools. Accessed at http://www. mff.org/pubs/ME165.pdf., 1999.

Moini, M. Spreadsheets in the Economics Classroom. Journal of Economics, 1996, 109-116.

Murray, M. Econometrics Lectures in a Computer Classroom. Journal of Economic Education, Summer 1999, 308-324.

Nicholson, W. Microeconomics. Boston: The Dryden Press, 1992.

No Child Left Behind Act of 2001. Pub. L. No. 107-110, 115, stat. 1425. http://frweb gate.access.gpo. gov/cgi-bin/getdoc.cgi?dbname=107_cong_public_laws\&docid=f:publ110. 107.pdf, 2002.

Owston, R., Murphy, S., and Wideman, H. The Effects of Word Processing on Students' Writing Quality and Revision Strategy. Research in the Teaching of English, 1992, 249-276.

President's Committee of Advisors on Science and Technology, Panel on Educational Technology. Report to the President on the Use of Technology to Strengthen K-12 Education in the United States Available at http://www.ostp.gov/PCAST/K-12ed.html., 1997.

Raef, C. Improving Student Writing Skills through the Use of Technology. ERIC Document Reproduction Service, April 1996.

Rodrigues, D. Computers and Basic Writers. College Composition and Communication, 1985, 336-339.

Russell, M., Bebell, D., Cowan, J., and Corbelli, M. An AlphaSmart for each student: Do Teaching and Learning Change with Full Access to Word Processors? Computers and Composition, 2003, 1-28.

Savage, H. and Law, D. The Practice Set: A New Spin on an Old Idea. Journal of Education for Business, Nov/Dec, 2003, 75-78.

Schacter, J. The Impact of Education Technology on Student Achievement: What the Most Current Research Has to Say. Santa Monica, CA: Milken Exchange on Education Technology, 2001.

Schmidt, S. Active and Cooperative Learning Using Web-Based Simulations. Journal of Economic Education, Spring 2003, 151-67.

Sivin-Kachala, J. Report on the Effectiveness of Technology in Schools, 1990-1997. Washington, DC: Software Publisher's Association, 1998.

Slattery, P. and Kowalski, R. On screen: The Composing Processes of First-Year an Upper-Level College Students. Computers and Composition, 1998, 61-81.

Waxman, H., Connell, M., Gray, J. A Quantitative Synthesis of Recent Research on the Effects of Teaching and Learning with Technology on Student Outcomes Naperville, Ill.: North Central Regional Educational Laboratory. www.ncrel.org. 2002.

Wenglinsky, H. Does it Compute? The Relationship Between Educational Technology and Student Achievement in Mathematics. Princeton, NJ: Policy Information Center, Research Division, Educational testing Service, 1998. 